\title{
The Impact of Smartphone on Universitarian Psychological Wellbeing
}

\author{
Augusto da Costa $^{1}$, Agostinho Dos Santos Goncalves ${ }^{2}$, Sebastiao Pereira ${ }^{3}$, Imanuel \\ Hitipeuw $^{4}$ \\ \{acostas3bk2015@gmail.com ${ }^{1}$, santosagostinho@yahoo.com² ${ }^{2}$, sebastiao.cristal@yahoo.co.id ${ }^{3}$, \\ imanuel.hitipeuw.fip@um.ac.id $\left.{ }^{4}\right\}$ \\ Instituto Superior Cristal, Timor Leste ${ }^{123}$ \\ Universitas Negeri Malang, Indonesia ${ }^{4}$
}

\begin{abstract}
The purpose of this study to discover the impact of Smartphone on human psychological well-being. This study is done from the perspective of Empirical Phenomenological Research, Qualitative. The method to collect the data is observation and inventory / an unstructured interview. The observation is done among Timorese universitarian in Malang. At the same time, had been done an interviewed on 15 subjects. The analysis the data is using descriptive through phenomenological, eidetic and transcendental reduction. The Result of the research shown that there are two impacts of the smartphone on universitarian such as positive negative. There are positive impacts because the utilization of smartphone is facilitating universitarian to reach psychological wellbeing. It became a smartphone been used to obtain well-being by communicating and chatting with family and friends. The further positive function is facilitating universitarian to develop their human resources/skill by studying. The negative impact was the frequencies of using the smartphone. Some universitarian used most of their time to play games (irritating - eyes). Some of them are using headset frequently it is trouble for hearing. Therefore universitarian needs to wisely use the smartphone.
\end{abstract}

Keywords: Universitarian, smartphone, psychological wellbeing

\section{Introduction}

Nowadays, at 4.0 industrial revolution, technology become an essential element of every people in their daily life[3]. One of the most useful product of the technology is smartphone. Smartphone become most influential communication instrument for almost every human being, including college student. The college student become subject at this study. Mirroring on essentiality and influentially of smartphone for the college student; it can be formulated that smartphone is bringing psychological well-being [4][5]. Based on the reason that been mentioned above, can raised some philosophical and psychological questions. The questions are: Who college student is? What smartphone is? How smartphone become an essential element of college student? What is the impact of smartphone towards college student's psychological well-being? How smartphone impact toward college student's psychological well-being?

Those questions become a direction for this study. Almost each one knew the answer of who college student is? However in academicals circumstance it needs specific definition. College student are young man and woman that has finished they Senior high school and starting their study at the university in a specific area of scientific. The main objects of the 
college students are elaborating academic, social, psychological, spiritual and personal knowledge and skills in their chosen and interested area. Those various skills and knowledge are enabling them to be more useful manner in daily and society life. To elaborate those skills and knowledge the college student need an instrument. The one of the most important and become unchanging instrument is smartphone.

As everyone knew that smartphone is essential communication instrument that facilitate college student to be able to elevate and to develop all skills and knowledge's. Smartphone become unchanging instrument for college student to develop the soft and hard skill [6]. Beside as instrument to develop skills and knowledge, smartphone also become means for the college student to get psychological well-being. It means smartphone can be utilized by college student to find out the way and the collusion on their problems of life. One of the most college student problems of studying or learning new skills and knowledge [9]. The one good option that college student must use to overcome their daily problems in learning is seek helping from the professional person. Professional one that can help college student to be able to overcome their learning problems is counselor. It means college student must use smartphone to contact and to share their daily problems with the counselor.

College student used smartphone to obtain the psychological well-being. All the university was interesting to increase the psychological well-being of the college student. The reason was university wanted to produce a happiness and well-being college student. The college student that obtain well-being be enabled to learn best. The best college student was result of the balance psychological well-being and learning. Well-being strengthen and encouraged college student to mode effective, creative, efficacy in learning. The positive spirit of college student was associated with curiosity in learning new skills and knowledge by smartphone.

\section{Method}

This study was using phenomenological qualitative research [13]. Phenomenology means this study conducted beyond the phenomenon that undergoing between college students. One phenomenon that most actual among college student is utilizing the smartphone. In regards to the data collected through two qualitative instrument. Those two instrument were observation and unstructured interview (Smith, 2008; Parsons, 2012; Mukhopadhyay \& Gupta, 2014). Observation was done among college student from fourth private universities and an institute in Malang city. Those observation data was completed by unstructured interview toward 15 subject. Those 15 subject was composed of three subjects from each universities and an institute.

There were three steps that been used to conduct this study such as phenomenological reduction, eidetic reduction, and transcendental reduction (Brown, 2011; Mapiare, 2012). At phenomenological reduction the action that needs to be done was summarizing and abstraction the empirical observation data into direct meaning. At eidetic reduction research move furthermore from phenomenon up to essence of the phenomenon as researcher. The last step is transcendental reduction at this stage research enter into individual concept such as ego in relating to ego of research subjects. The research data set can be accessed in osf.io Open Science Framework. 


\section{Finding and Discussion}

Through observation has been identified two impacts smartphone toward psychological college student well-being such as positive and negative. At least, seven positive values of smartphone that been observed including: learning, searching, communicating, discussing, consultation, problem solving, saving. On the other side, was existing sixth negative impact of smartphone such as unhealthy, cutting, and addiction, expending, exposing, and wasting time and money.

The positive impact of smartphone was learning the technology of information.

1. The college students used smartphone to develop and to elevate their skills and knowledge in regards to technology and information. Smartphone facilitate college student learn more the way to use technology to discover the all information that spread in this globe (Liyanage et all, 2013).

2. Smartphone also enable college student to enrich their learning skills by searching the learning materials on the internet. At this digital era, college student be facilitated to access easily the internet to get all the learning material that was needed.

3. Smartphone facilitated college students to communicate with this family. The subject of this research can communicate with their family that been left behind in their home village by smartphone. In the communication the college student can share information with their family at long distances. The information that they share in relating to all aspects of their daily life that been experienced in foreign place, including study. At the sharing they can get all supports that was needed from the family.

4. Smartphone enable college student to discuss with the academic instructors. Through Discussion College student got important information in relating to the academic aspect by discussing with their instructors. The instructors also be able to share, to guide and to direct student through smartphone even though in far distance.

5. Based on the observation indicated that some of college student faced problems. Those problems was relating to the learning and studying process. Sometimes, in learning process college student faced hugs problems to fully understand the subject be lectured by their lecturers or instructors. The problem may cause them stress at some stages. In stressing Situation College students needed someone professional to guide them through that experiences. The professional the mostly helped student in relating to the study stress was counselor. Smartphone was enabling college student to contact and to find helping from counselor.

6. Helping that college student got from the university counselor, encouraged them to overcome the learning problems that been faced. After having solution of their problems college student be able to study more focus. Focusing in the learning helped them to be mode skilled.

7. Smartphone helped college student in saving time and money. Saving time in this understanding means student invested short time to get whatever was expected. For example college at this era used smartphone to search and to download all the learning materials that they need in few minutes. If compare with previous era student invested most of their time to go to the library for seeking the learning material that be needed. Furthermore college student at this era was using smartphone to communicate and to talk 
with a counselor easily, compare with the college student at previous era counselee have to go to the counselors place[11]. The consequences of the save time was saving money. Smartphone facilitated college student searching the learning materials that be needed, they were no need to spend a lot of money to buy all books that they need.

Beside these seven positive impact, discover also five negative impact of smartphone toward psychological college student well-being.

1. The first negative impact of using smartphone that been observed was in medical unhealthy. It means using the smartphone most frequently can impacted on medical unhealthy. The main medical problems was irritating of eyes and reducing the sensitivity of hearing of smartphone user among the college student. Some the smartphone user among college student had suffered problems of eyes because of radiation of smartphone lightening. Holding smartphone too near to the eyes caused irritating. The intensity of irritating caused diminishing eyes vision. This condition pushed smartphone user to use the eye glasses. At the same time college student that used smartphone and headset most frequently can reduced hearing. The reducing function of eyes and hearing brought problems in process of learning and studying. Problem in learning process brought college student to the psychological tension. Intensity of psychological tension caused college student far from the psychological well-being.

2. Using the smartphone mostly time can bring user into the deteriorated consciousness. It can be named addiction. The experiences of addiction difficulties user to come out from that situation. Everyone knew that someone has addictive to something, it associated with negative perception. Those addictive college student directly and indirectly faced alienation feeling and thinking from others. Addictive habit can be named a psychological problem [22].

3. The further negative impact of using smartphone was reducing direct social interaction. It means that college student used most of the time to use smartphone for playing various online games, not be able to personally and physically contact with other people. At this situation college student was cut off from the social direct interaction. The consequences of the lack of social direct interaction can caused college student isolated from other. The feeling of isolation bring college student into the psychological problems.

4. The next negative impact of using smartphone for the college student exposed to the negative contain in the cyberspace [3]. It was including hoax information about some public figure. The smartphone user that has habit of exposing negative information become unbalance and emotional person. Emotional person do something according to their own perspective, perception and thinking. College student that guided by personal unbalance perspective, perception and thinking can become an extreme in speaking and doing. It will bring negative impact toward other people in the society. If it was not handle properly will cause more detriments for them self and for other in large scope of society.

5. The last observation data about the negative impact of utilizing smartphone was wasting time and money [23]. Has been observed that some college students used most of the time to play various online games. Game can be played everywhere and any times because smartphone was always in their hand. The online game needed internet connection. Mostly internet connection needed money to buy voucher or internet packet. Packaging in 
internet has time limit depend of kind and quality of sim card. Some sim card offer time limit one month, three months, sixth months or one year with capacity some gigabyte. The time limit was set by Telecommunication Company to provoke user to be depend of it. The observation data shown that some time the time limit packet that duration for one month, three, sixth months or one year not exactly same, depend on activating and using time. If the smartphone connected to internet in every single time, it will consume a lot of vouchers. It means dependency of smartphone using needed plenty of money to buy internet packages[24].

Those result of finding based on observation date was reinforced by unstructured interview toward 15 subjects. All of the subjects recognized those two elements of impact. The positive and negative impact of smartphone toward psychological well-being[10]. Subjects described that among the college student in their own university mostly performed positive and negative impact of smartphone. Subjects said that some college student realized and conscious in using smartphone. This group knew the way to utilize the smartphone. Mostly of this group were using smartphone to search the learning material. Some of college student used smartphone to communicate with the family and relatives, some were using to communicate to the lecturers and instructors. The other college student utilized smartphone to communicate with counselors for seeking of guidance and counseling[1].

On the other hand subject summarized that there were some of their fellow's college student expressed the negative impact on smartphone in everyday life. Some college student was using smartphone in unhealthy ways. Some were cutting off from the social direct interaction. At the same moment, few college student became addiction to the smartphone. So far there were very few of them was exposing negative contents in their status whatsApp and at instagram[12]. Fortunately after having addressed by some senior college students the negative contents was disappeared. Subjects recognized also some senior and junior college student were wasting a lot of time played various online games with their smartphone. Some of the misused smartphone was recovered after having guidance and counseling services. It means the presence of the campus counselor was important.

The counselor presence to implement four components guidance and counseling services such as basic service, responsive services, individual planning and system support [25]. These four components of guidance and counseling services should be understand in framing of comprehensive guidance counseling. Comprehensive guidance and counseling aimed to address: (a) attainment personal adequate to self-understand, to understand others and environment, (b) comprehensive services, (c) psychological development of counselee, (d) personal and social interaction, (e) harmonization between personal and environment.

Based on the finding that been described above can be concluded two main impacts of using smartphone toward college student psychological well-being. There was positive and negative impacts. The positive was bringing good psychological well-being for college student, because smartphone facilitate college student to develop expects personal, behavior, cognitive, social and psychology. On the other side, smartphone have negative impact toward college student psychological well-being in terms of eyes irritating, hear reducing, addictive social isolation, exposing negative content through hoax, wasting time and money. This negative impact can be solved to be positive if campus counselor accompany college student to develop a positive attitudes in dealing with smartphone.

Stand on this finding can be offered three solution for every user smartphone. The first, college student need to conscious the purposes of possessing a smartphone. This consciousness be able to increase the critical thinking. The critical thinking is most important 
cognitive element that must be possessed by college student. Second, college student have to know the positive and negative impact of smartphone on physical and psychological condition. Third, college student have responsibility in using smartphone to self, society and environment. Fourth, the college student should utilize wisely the smartphone, specially using it for developing the positive behavior, cognitive, psychology, moral, psych spiritual, environment and social direct interaction.

\section{References}

[1] N. B. Priya and I. Juvanna, "An Android Application for University Online Counseling," Int. J. Comput. Sci. Mob. Comput., vol. 3, no. 2, pp. 261-266, 2014.

[2] V. K. (Strategy\&) and S. K. (Strategy\&) D. Dr Reinhard Geissbauer (PwC), Stefan Schrauf (PwC), "Industry 4.0 - Opportunities and Challenges of the Industrial Internet," pp. 1-52, 2014.

[3] S. Bligh-wall, "Industry 4 . 0: Security imperatives for IoT converging networks , increasing risks," vol. 1, pp. 61-68, 2017.

[4] A. K. Vesely, D. H. Saklofske, and A. D. W. Leschied, "Teachers-The Vital Resource: The Contribution of Emotional Intelligence to Teacher Efficacy and Well-Being," Can. J. Sch. Psychol., 2013.

[5] A. P. Plominski and L. R. Burns, "An Investigation of Student Psychological Wellbeing: An Investigation of Student Psychological Wellbeing: Honors Versus Nonhonors Undergraduate Education," no. October, 2017.

[6] S. Jeong and C. Breazeal, "Improving Smartphone Users ' Affect and Wellbeing with Personalized Positive Psychology Interventions," pp. 131137, 2016.

[7] H. S. Albarashdi, A. Bouazza, N. H. Jabur, and A. S. Al-zubaidi, "International Journal of Psychology \& Behavior Analysis Smartphone Addiction Reasons and Solutions from the Perspective of Sultan Qaboos University Undergraduates : A Qualitative Study," vol. 2, 2016.

[8] H. Kumcağiz and A. P. Yü, "Relationship between Psychological Well-Being and Smartphone Addiction of University Students," vol. 5, no. 4, pp. 144-156, 2016.

[9] G. Development and U. T. Mara, "The Relationship Between Smartphone Use and Academic Performance: A Case of Students in a Malaysian Tertiary," vol. 5, no. 4, pp. 58-70, 2017.

[10] B. Woodcock, A. Middleton, and A. Nortcliffe, "Considering the Smartphone Learner: an investigation into student interest in the use of personal technology to enhance their learning," vol. 1, no. 1, pp. 1-15, 
2012.

[11] R. C. King, "Ihe impact of smartphone on young adults," vol. 8, no. 4, pp. 342-349, 2017.

[12] R. Dwyer, K. Kushlev, and E. Dunn, "Journal of Experimental Social Psychology Smartphone use undermines enjoyment of face-to-face social interactions ל," J. Exp. Soc. Psychol., no. March, pp. 0-1, 2017.

[13] G. Gimenez and J. P. Pinel, "A Proposed Method of Group Observation and Note-Taking from a Psychoanalytical Perspective," Gr. Anal., vol. 46, no. 1, pp. 3-17, 2013.

[14] T. F. Smith, "Integrative Literature Review: Methods in Identifying Exemplary Performance: A Review of the Literature and Implications for HRD," Hum. Resour. Dev. Rev., vol. 7, no. 4, pp. 443-468, 2008.

[15] S. A. Parsons, "Adaptive Teaching in Literacy Instruction: Case Studies of Two Teachers," J. Lit. Res., vol. 44, no. 2, pp. 149-170, 2012.

[16] S. Mukhopadhyay and R. K. Gupta, "Survey of Qualitative Research Methodology in Strategy Research and Implication for Indian Researchers," Vis. J. Bus. Perspect., vol. 18, no. 2, pp. 109-123, 2014.

[17] M. V. Brown, "How they cope: A qualitative study of the coping skills of hospice volunteers," Am. J. Hosp. Palliat. Med., vol. 28, no. 6, pp. 398 402, 2011.

[18] L. Liyanage, R. Strachan, R. Penlington, and B. Casselden, "Design of educational systems for work based learning (WBL): the learner experience," High. Educ. Ski. Work. Learn., vol. 3, no. 1, pp. 51-61, 2013.

[19] A. R. Lundquist, E. J. Lefebvre, and S. J. Garramone, "Smartphones : Fulfilling the Need for Immediacy in Everyday Life, but at What Cost? 1600 Burrstone Road," vol. 4, no. 2, pp. 80-89, 2014.

[20] M. Sarwar, "Impact of Smartphone 's on Soci ety," vol. 98, no. 2, pp. 216-226, 2013.

[21] B. L. Miakotko, "The impact of smartphones and mobile devices on human health and life," 2017.

[22] M. Harris, M. Martin, and D. Martin, "The Relationship Between Psychological Well-Being and Perceived Wellness in Graduate-Level Counseling Students," vol. 3, no. June, pp. 14-31, 2013.

[23] C. Pearson and Z. Hussain, "Smartphone Addiction and Associated Psychological Factors Smartphone Addiction and Associated Psychological Factors *," no. October, 2016.

[24] T. N. Friemel, "The digital divide has grown old: Determinants of a digital divide among seniors," New Media Soc., vol. 18, no. 2, pp. 313-331, Feb. 2016.

[25] A. K. Suhag, A. M. Pirzada, H. M. Butt, A. A. Butt, F. Zeb, and F. 
Raza, "G UIDELINE A guideline for Establishing a New Guidance and Counseling Center in School," vol. VOLUME 2, no. ISSN: 2207-4236, pp. $1-5,2017$. 